The Journal of Animal \& Plant Sciences, 30(5): 2020, Page: 1106-1114

ISSN (print): 1018-7081; ISSN (online): 2309-8694

\title{
EFFECTS OF ENTEROCOCCUS FAECIUM (SF68) SUPPLEMENTATION ON THE INNATE IMMUNE DEFENSES AND BLOOD BIOCHEMICAL CHANGES IN PRE- WEANING GOAT KIDS
}

\author{
A. Tiantong ${ }^{1 *}$, P. Piamya ${ }^{2}$, C. J. Chang ${ }^{2}$ and S. E. Chen ${ }^{2}$ \\ ${ }^{1}$ Faculty of Animal Sciences and Agricultural Technology, Silpakorn University, Phetchaburi IT Campus, Phetchaburi, \\ 76120 Thailand \\ ${ }^{2}$ Department of Animal Science, National Chung Hsing University, Taichung, 402 Taiwan \\ *Corresponding Author's email: tiantong_a@su.ac.th
}

\begin{abstract}
A commercial probiotic strain Enterococcus faecium 68 (SF68) was supplemented to the first day colostrum continued with the commercial milk replacer until weaning day (35 days) in newborn goat kids to evaluate its efficacy as a probiotic on the innate immunity and blood biochemical parameters. Blood samples were collected at 2, 12, $24 \mathrm{~h}$ after birth, and at day 5 and 7, and thereafter at weekly intervals until the end of the experiment (day 35). Plasma protein and immunoglobulin content, leukocyte count, and leukocyte reactive oxygen species (ROS) production were analyzed. Results suggested that the count of blood leukocytes increased continuously up to day 35, especially in SF68supplemented group. Plasma protein content peaked at 12-h of age regardless of SF68 supplementation. The abundance of plasma $\gamma$-globulins also increased to reach the top at 12-h and goat kids with the SF68 supplementation had higher levels of plasma $\gamma$-globulin and albumin. The ROS production of blood leukocytes increased continuously up to day 35 , and the increase was more dramatic in goat kids fed with SF68 supplementation. The results suggested that SF68 supplementation in goat kids can benefit innate immunity of goat kids before weaning.
\end{abstract}

Key words: Enterococcus faecium SF68, colostrum, goat kids, leukocyte ROS production.

https://doi.org/10.36899/JAPS.2020.5.0126

Published online June 25, 2020

\section{INTRODUCTION}

For a long time, farmers in Thailand has been looking for feed management and products to improve the performance of livestock, especially the health of neonates. In Thailand, and around the world, antibiotics have been commonly used to promote both health and growth in a variety of domesticated animals (Wongsuvan et al., 2018) and have been shown to be effective in acting against pathogens by supporting the immune system. However, there are also adverse outcomes resulting from the use of antibiotics. In particular, bacterial populations can build resistance to the antibiotics used, so to prevent this from occurring, farmers in the European Union have no longer been permitted to use antibiotics to encourage stronger growth following measures introduced in 1999 (Abe et al., 1995; Casewell et al., 2003). The prohibition has led to poor animal performances and increased the incidence of certain animal diseases. Thus, there is urgently required to find alternatives replace antibiotics for better performance of domestic animals.

Systemic immune responses can be modulated by probiotic bacteria through the gut-associated immune system (Gill et al., 2001; Schultz et al., 2003; Braat et al., 2004; Pohjavuori et al., 2004). In this process, the probiotic bacteria are able to pass in a paracellular manner through the epithelial cells found in the Peyer's patches, thereby serving to activate those immune cells which perform a surveillance role (Maldonado et al., 2007). Probiotic bacteria can be especially helpful through their influence upon local and systemic immune systems, and therefore have potential to be used to better the health of livestock and serve as an alternative to the use of antibiotics in addressing the threat from pathogens. A majority of the probiotic bacteria to which livestock would be exposed are of the type of indigenous microbiota which can be found in the intestine of the host. Studies have shown that immune systems of domestic animals can benefit from the dietary use of the Enterococcus faecium strain SF68 (SF68) which is a gram-positive endospore-forming bacteria first obtained in Sweden using the feces of a healthy baby (Veir et al., 2007; Simpson et al., 2009; Bybee et al., 2011). Similar benefits were found when the bacteria were isolated from pigs (Scharek et al., 2005; Broom et al., 2006; Scharek et $a l ., 2007)$. In the case of newborn animals, it is essential to consume high quality colostrum in adequate quantities during the initial 24 hours after birth in order to ensure the productivity and general health of the animal as it develops (Gay, 1983; DeNise, 1989). Passive transfer of colostrum immunoglobulins is a critical prerequisite for neonate animal health and survival, which can reduce the 
mortality rate during the preweaning period. Poor formation, ingestion, or absorption of colostrum-derived immunoglobulin factors results in a failure of passive of immunity (FPT), leading to an increased risk of infection and thereby higher rates of mortality along with adverse consequences for the longevity, health, and productivity of the members of the herd (Poulsen et al., 2010). This study was therefore conducted with the aim of assessing the effects of probiotic bacteria upon the innate systemic immune response and the biochemical changes in the blood of goat kids. Plasma protein content and the ROS production capacity of blood leukocytes were accessed as indicators of the health and general anti-bacterial potential in the goat kids.

\section{MATERIALS AND METHODS}

Animals: Ten healthy newborn goat (2 Toggenberg, 3 Nubian, 3 Saanen, and 2 Alpine) at birth weighed ranging from $3.0-4.0 \mathrm{~kg}$ with normal appetite and activity were used in the study. The study was conducted with the goat kids in weaning period immediately after birth to the age of 35 days. Goat kids were randomly divided into two treatments with five animals per treatment; Treatment A, goat kids were provided with doe's colostrum within $2 \mathrm{~h}$ and then were fed commercial cow milk replacer without probiotic supplementation (control) twice daily at approximately 0700 and $1600 \mathrm{~h}$ till day 35 of age; and treatment B, Enterococcus faecium 68 (SF68) strain (1× $10^{9} \mathrm{CFU} /$ feeding) was supplemented into doe's colostrum within $2 \mathrm{~h}$ and continue to supplement in the milk replacer in the morning meal at day 7 , day 14 , day 21 , and day 28, respectively. Throughout the study, goats were housed indoors in raised pens with slotted floors. A commercial starter diet containing $18 \%$ crude protein, $3.5 \%$ crude fat and $14 \%$ crude fiber was provided at 7 days of age. Water and mineral salts were available ad libitum. Approval for the use of animals in the study was granted by the Animal Use and Care committee of the Faculty of Animal Sciences and Agricultural Technology, Silpakorn University Phetchaburi IT Campus, based on the Ethic of Animal Experimentation of National Research Council of Thailand.

Weighing of the animals: All animals of both groups were weighed immediately after birth (0-day of age) and at 7-day of age, at 21-day of age, and 35-day of age.

Sampling: Peripheral blood samples of goat kids were collected from the jugular vein prior to the first colostrum feeding $(<2 \mathrm{~h})$, and then before morning meal feeding after 5 days, 7 days, 14 days, 21 days, 28 days, and 35 days, respectively. All samplings were performed aseptically and transported in ice bath for immediate preparation.
Sample preparation: Samples of blood were placed in heparinized tubes and centrifuged at $1800 \mathrm{x} g$ for $30 \mathrm{~min}$ at $4{ }^{\circ} \mathrm{C}$ in order to separate the plasma from its particulate fractions. Plasma was stored in aliquots under $-20^{\circ} \mathrm{C}$ for further analyses within two weeks. Red blood cells in the particulate fraction was lysed (BioLegend, San Diego, $\mathrm{Ca}$, USA) and the remaining leukocytes were subsequently rinsed using ice-cold Dulbecco's PhosphateBuffered Saline (DPBS, without $\mathrm{Ca}^{+2} / \mathrm{Mg}^{+2}$; SigmaAldrich) before suspension in Hanks' balanced salt solution (HBSS, enriched with $0.25 \mathrm{mM} \mathrm{Ca}{ }^{+2} / \mathrm{Mg}^{+2}$; Sigma-Aldrich). The HBSS leukocyte suspension was enumerated under microscope, and volume of HBSS suspension necessary for immediate assay of ROS production capacity of blood leukocytes was calculated.

A dry-binding reagent (Bio-Rad Laboratories, Hercules, CA, USA) was used to determine the total plasma protein content using a microplate (Multiskan Ascent, ThermoLabsystems, Helsinki, Finland) using BSA (Sigma-Aldrich) to construct a standard curve for calculating the volume necessary for SDS-PAGE.

SDS-PAGE: The native SDS-PAGE (Laemmli, 1970) system was used to resolve the protein composition of plasma. The separation gel concentration was used at $7 \%$ acrylamide. For each sample, the amount of volume containing $10-\mu \mathrm{g}$ total proteins was used for to SDSPAGE (Minigel, Bio-Rad Laboratories, Hercules, CA, USA) to obtain the greatest band area per $\mu \mathrm{g}$ protein. Samples were firstly mixed with the $2 \mathrm{X}$ native sample buffer (Bio-Rad Laboratories) (pH 6.8, with $62.5 \mathrm{mM}$ Tris- $\mathrm{HCl}, 40 \%$ glycerol, $0.01 \%$ bromophenol blue) prior to separation using SDS-PAGE. Subsequently, staining of the gels was performed for $60 \mathrm{~min}$ using Bio-Safe ${ }^{\mathrm{TM}}$ Coomassie G-250 Stain (Bio-Rad Laboratories) followed by destaining for $30 \mathrm{~min}$ twice in distilled water for band visualization. The plausible protein components were identified on air-dried gel and the putative $\gamma$-globulin band was defined of 110 to $150 \mathrm{kDa}$ in size, and BSA was 50 to $60 \mathrm{kDa}$. The respective band image was captured with Epson Stylus TX130 (Seiko Epson Corporation, Nagano, Japan) and quantified by Image J software (v.1.50i; National Institutes of Health, Bethesda, MA, USA). The integrated band area was then adjusted for the amount of protein loaded and the greatest band area per $\mu$ g loading protein was obtained. The plasma samples collected on different days from the same animals were resolved on the same gel in parallel with the accepted standards for molecular weight (Precision Plus Protein Standards, Bio-Rad Laboratories).

Chemiluminescence assay for the ROS production capacity of cells: The phorbol 12-myristate 13-acetat (PMA)-stimulated assay (Peng et al., 2013; Tiantong et al., 2015b) was used to stimulate ROS production. To summarize, an aliquot of the fresh HBSS cell suspension which contained $1 \times 10^{6}$ blood leukocytes underwent 
initial maintenance for $10 \mathrm{~min}$ at $37^{\circ} \mathrm{C}$ before the introduction of 300- $\mu \mathrm{g}$ of $1 \mathrm{mM}$ luminol (Sigma-Aldrich) (in $0.1 \mathrm{M} \mathrm{DMSO} / 0.05 \mathrm{M} \mathrm{Na}_{2} \mathrm{CO}_{3} / 1.5 \mathrm{mM} \mathrm{CuSO}$ ). To perform the reading for chemiluminescence, $50-\mu 1$ of PMA stock solution (200 $\mu \mathrm{g} / \mathrm{ml}$ DMSO) with HBSS was added to the suspension, whereupon further HBSS was used to make up the final reaction volume to $\leq 1000-\mu$ l. The emission counts per second (CPS) was recorded instantly every $\min$ for $20 \mathrm{~min}$ in a luminometer (Triathler, type 425-014, Hidex, Turku, Finland). The ROS production capacity of cells was defined as the net response to PMA stimulation which was expressed as the area under CPS-time curve (AUC) after adjusting for the starting CPS value.

Statistical analysis: The data of body weight gain, total blood leukocyte count, ROS production capacity of blood leukocytes, total plasma protein concentration, and plasma protein composition were analyzed by analysis of variance (ANOVA) using a General Linear Model (GLM) procedure on SAS software (SAS, 2008). When differences among diet treatment means or treatment sampling date interactions were significant, the differences between paired means were tested with Duncan's new multiple range test. Differences were considered significant at $P \leq 0.05$. The results are presented as the mean values and standard error of the means.

\section{RESULTS}

Body weight gain: The average weights of goat kids increased with time course and SF68-supplemented goat kids had a higher body weight than the control throughout the trial although no statistically significant difference was found when $P>0.05$ (Figure 1).

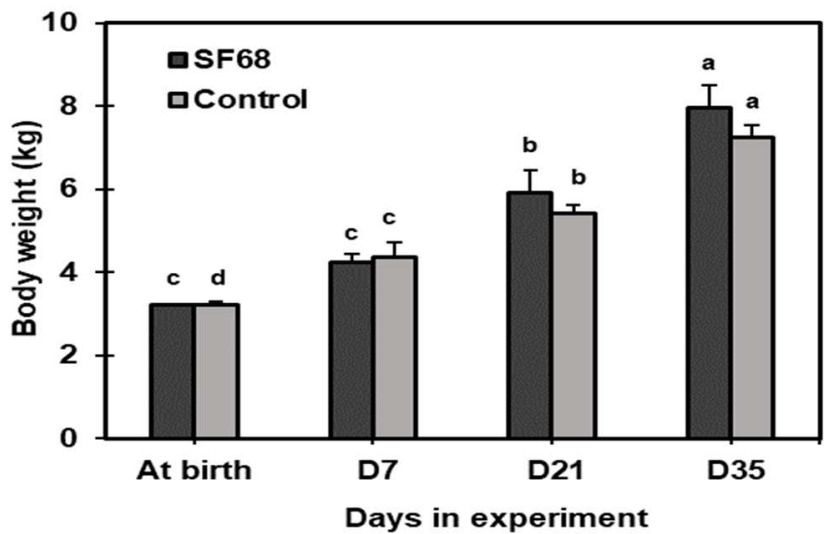

Fig 1. Effect of dietary supplementation of SF68 on body weight goat kids. a,b,c Those values which are indicated using a superscript were significantly different at the different time intervals within the same treatment at the significance level of $P<0.05$.

Total blood leukocyte count: The total blood leukocyte counts for goat kids with SF68 supplementation increased gradually to reach a top at day 5 , decline to day 21 and then increase again to reach another top at day 35, whereas the control goat kids exhibited a similar but lower increase of leukocyte counts to reach the top at day 5 , decline to day 21 , but remain a constant level to day 35 $(P<0.05$, Figure 2). The blood total leukocyte counts of SF68 group were found to be statistically significantly $(P<0.05)$ greater after $24 \mathrm{~h}$, day 5 , day 28 , and day 35 , when compared to the control group at a significance level of $P<0.05$.

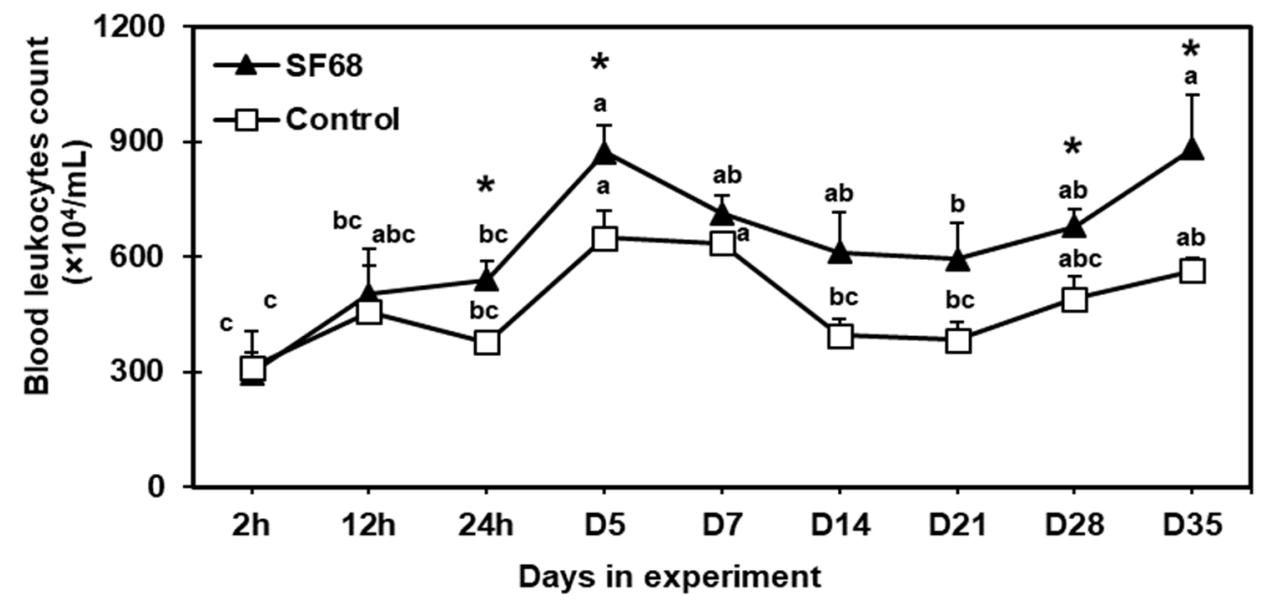

Fig 2. Effect of dietary supplementation of SF68 treatment on blood leukocyte counts. Values indicated by different superscript letters $(a, b, c)$ were significantly different among different times intervals within the same treatment at $P<0.05$ level. "; indicates a significant difference $(P<0.05)$ between SF68supplemented and control at the same time point. 
ROS production capacity of blood leukocytes: Similar to the blood total leukocyte count, ROS production capacity of leukocytes from SF68-supplementation goat kids increased gradually to reach a top at day 5, declined to day 21 and then increased again to reach another top at day 35 , whereas the control goat kids exhibited a similar but lower production to reach the top at day 5 , decline to day 21 , but remain constantly to day $35(P<0.05$, Figure 3 , panel A). Consequently, ROS production capacity of blood leukocytes of SF68 group was significantly $(P<0.05)$ higher at $24 \mathrm{~h}$, day $5,7,14,35$ than those of the control group $(P<0.05$, Figure 3, panel B).
(A)
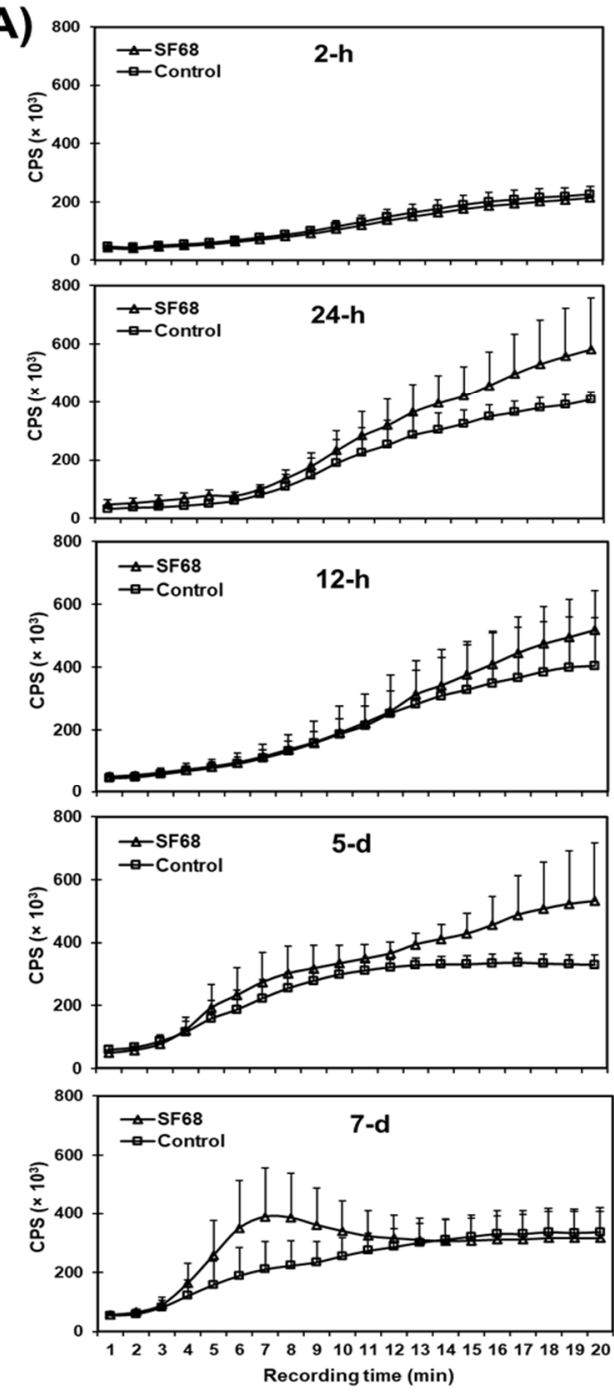

Total plasma protein concentration: In both
groups, total plasma protein concentration increased group for similar time intervals.
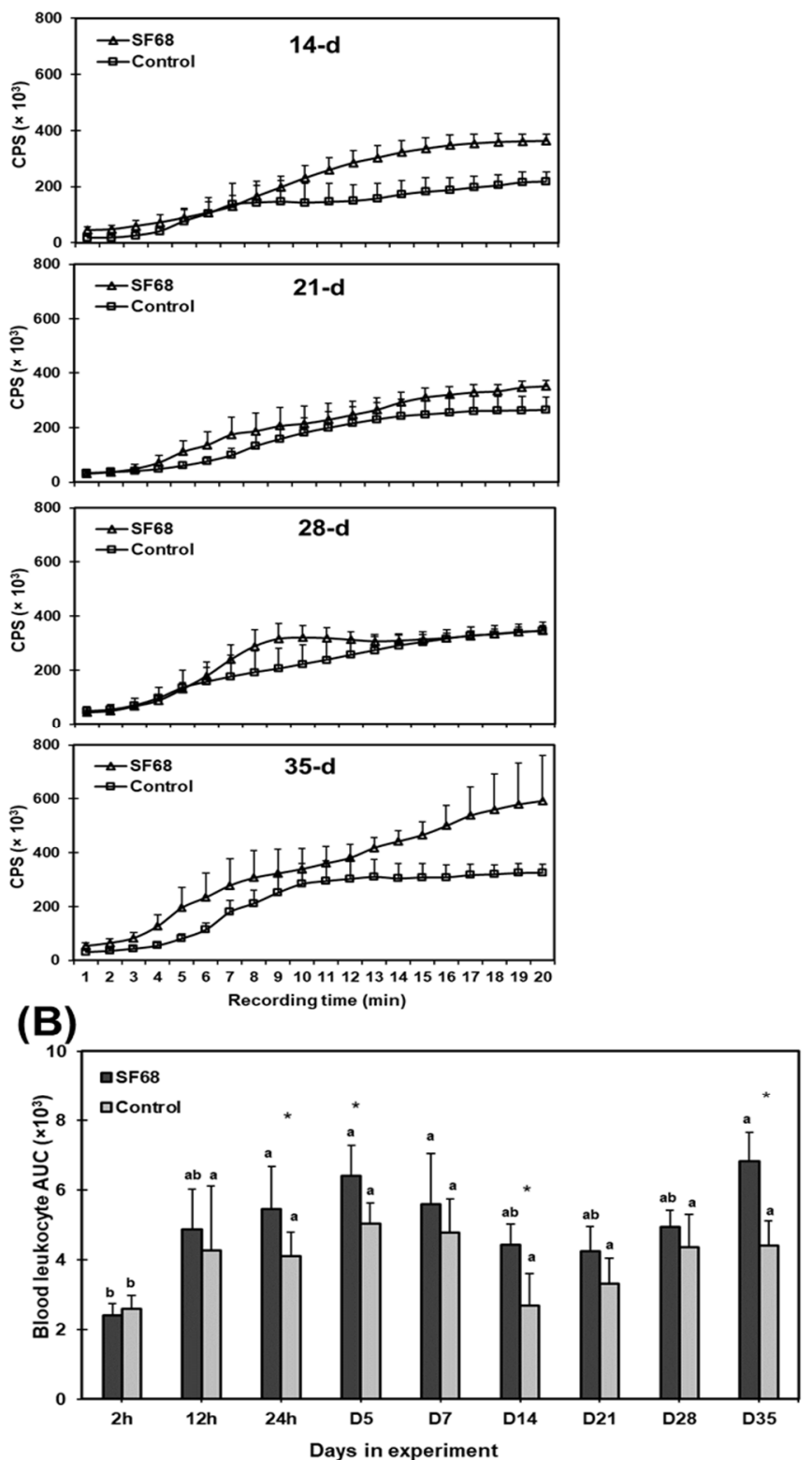

Fig 3. Effect of dietary supplementation of SF68 treatment on ROS production of peripheral leukocytes. Representative profiles of ROS production using CPS (counts per second) were shown in panel A. The corresponding area under the CPS times curve (AUC) after adjusting for the different starting CPS value at 1 min were shown in panel $B$. ${ }^{a, b, c}$ Those values which are indicated using a superscript were significantly different at the different time intervals within the same treatment at the significance level of $P<0.05$. "Significant differences $(P<0.05)$ were observed between the SF68-supplemented and the control

dramatically at $12 \mathrm{~h}$ then decreased and maintained a constant level thereafter, in which SF68 supplemented 
goat kids had a significantly higher plasma total protein level at 12 , and $24 \mathrm{~h}$ than the control. $(P<0.05$, Figure 4$)$.

Plasma protein composition: A typical plasma total protein profile was shown in Fig. 5. Visually, the putative $\gamma$-globulin and albumin bands represented the most distinguishable protein components. The means and SE of quantification results for the abundance of $\gamma$-globulin and BSA (band area/ $\mu \mathrm{g}$ protein) were shown in Fig.6. The abundance of $\gamma$-globulin was significantly increased
$(P<0.05)$ at intervals of both $12 \mathrm{~h}$ and $24 \mathrm{~h}$ in comparison to the observation at $2 \mathrm{~h}$ (pre-colostrum fed). It was also shown that the level of $\gamma$-globulin was statistically significantly greater at $12 \mathrm{~h}$ for the experimental group when compared to the control group at the significance level of $P<0.05$. Moreover, plasma albumin was observed in significantly greater levels after $12 \mathrm{~h}$ in the experimental group when compared to the control group at the significance level of $P<0.05$.

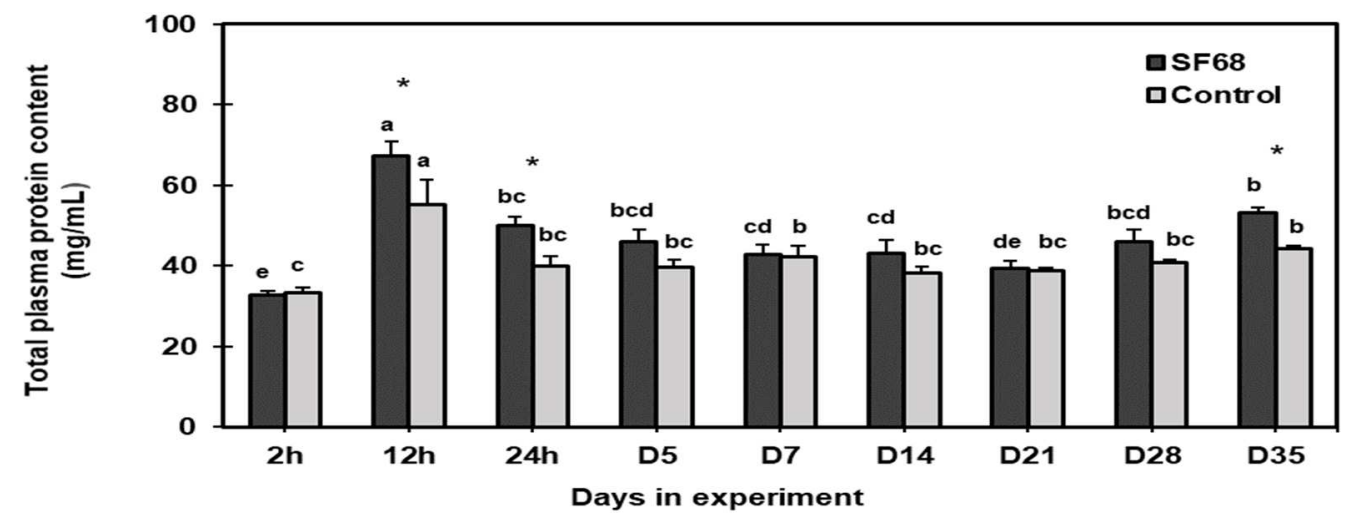

Fig 4. The influence of diet supplements involving SF68 treatment upon the total level of plasma protein. a,b,c Those values which are indicated using a superscript were significantly different at the different time intervals within the same treatment at the significance level of $P<0.05$. "Significant differences $(P<0.05)$ were observed between the SF68-supplemented and the control group at similar time intervals.

(A)

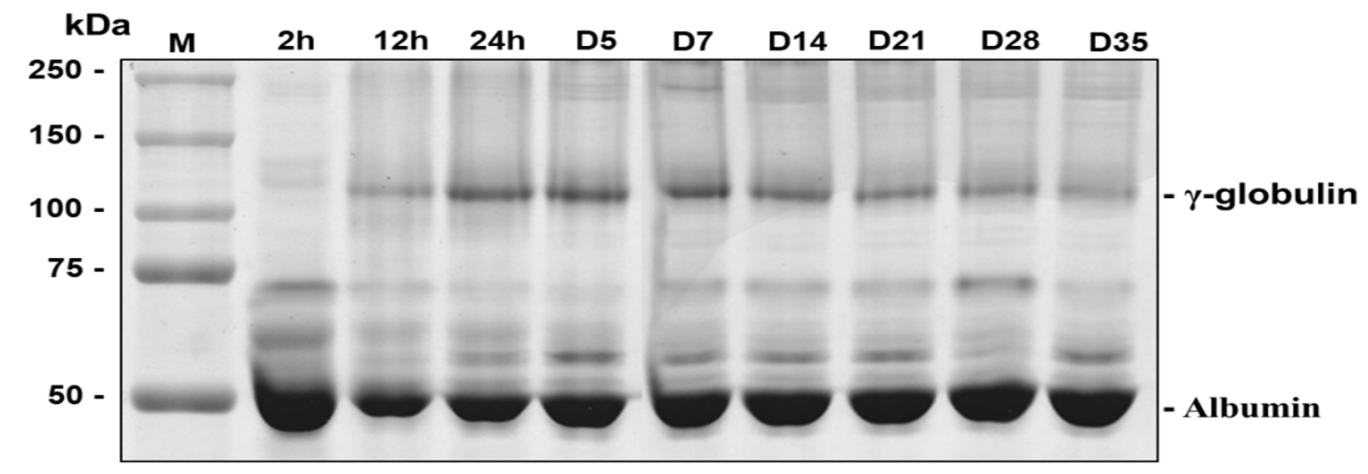

(B)

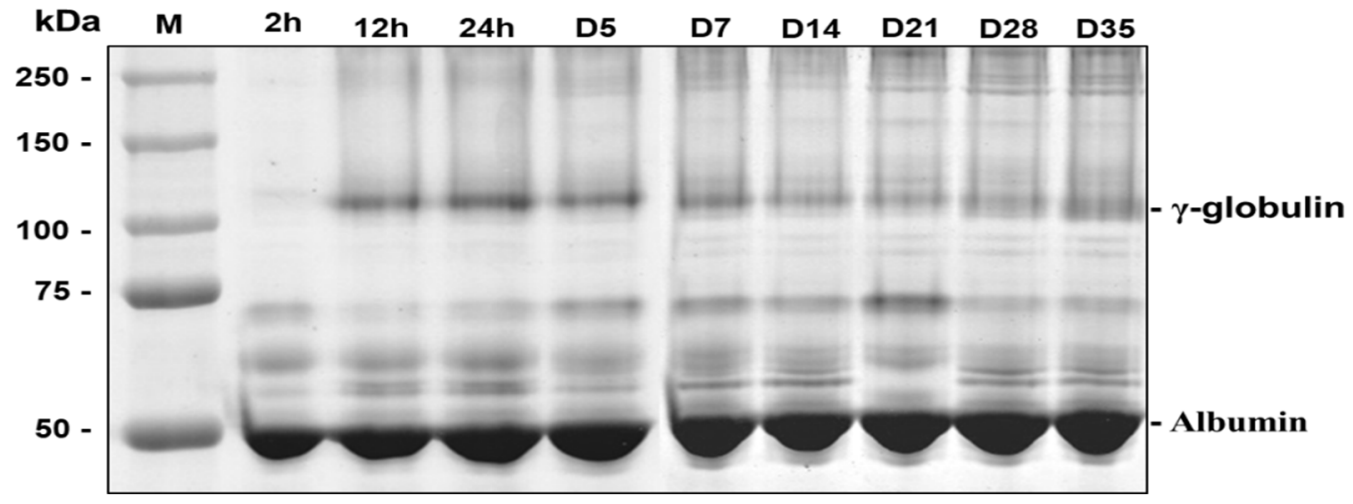

Fig 5. The total protein profile for plasma. The findings were obtained by $7 \%$ SDS-PAGE using samples from goat kids using SF68-supplements (panel A) and control group (panel B). 
(A)

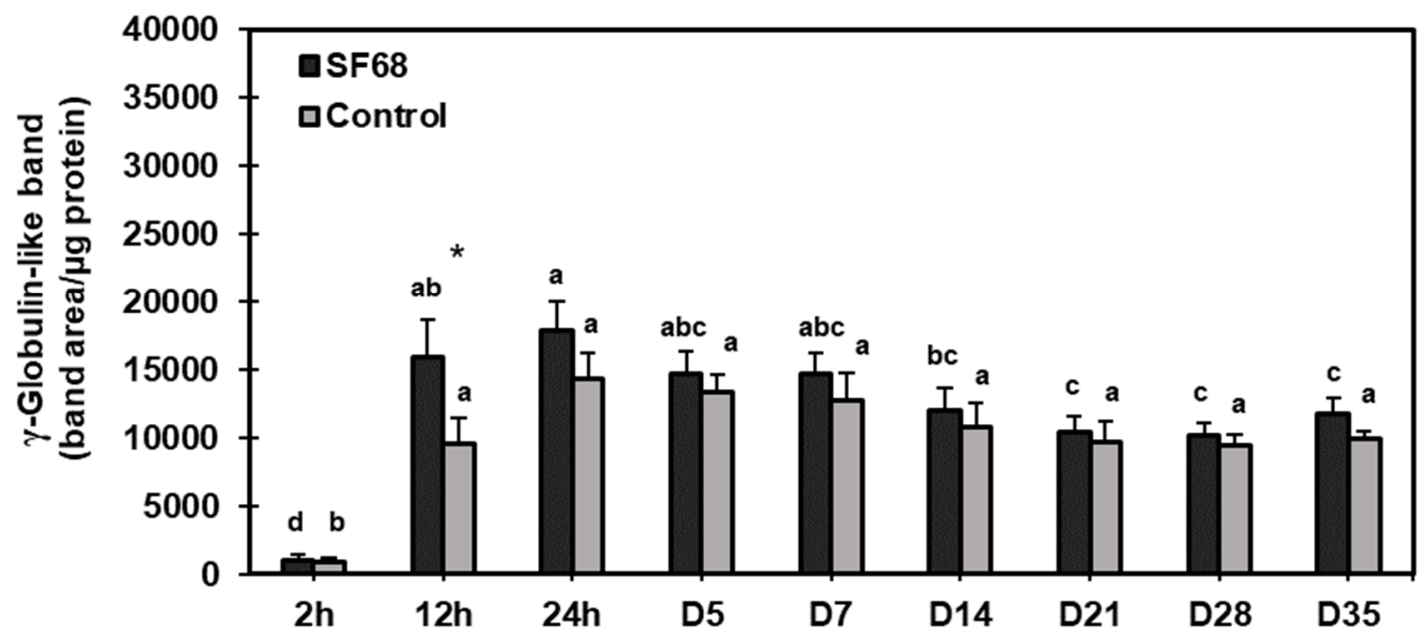

(B)

Days in experiment

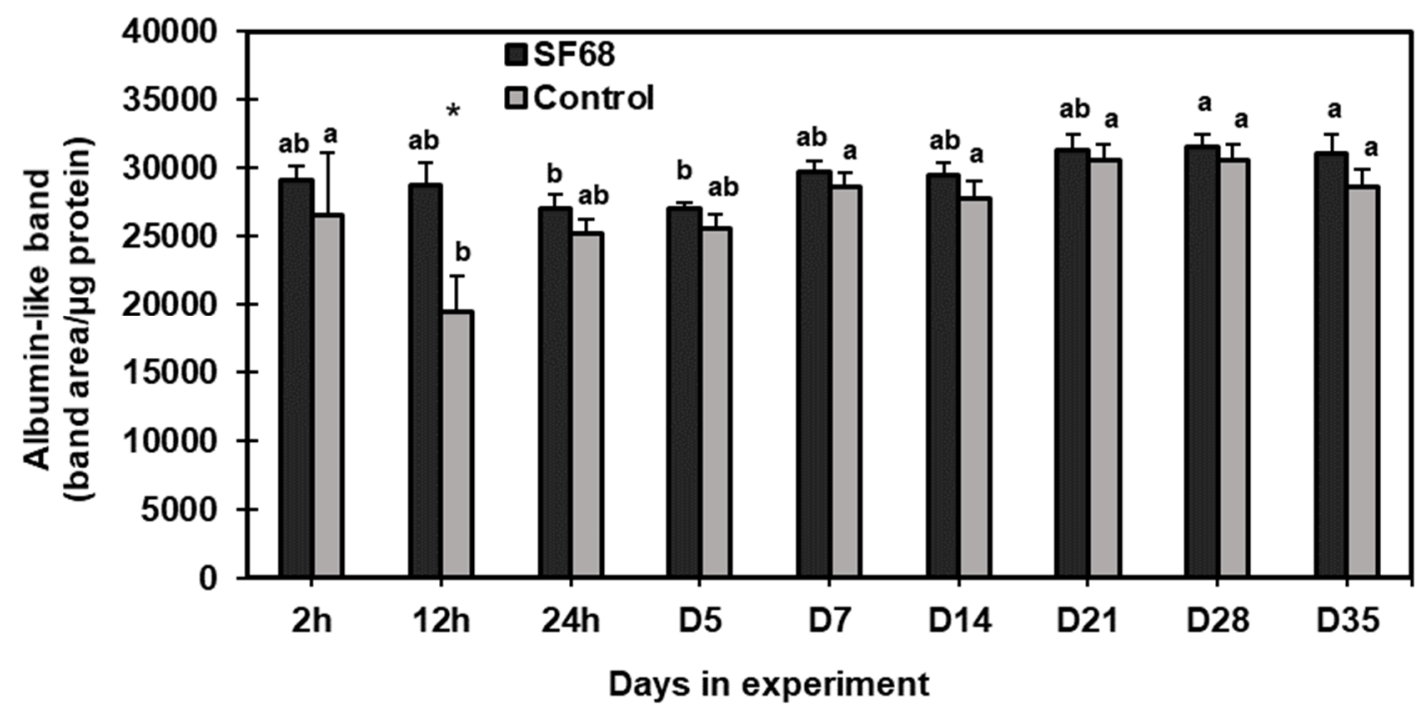

Fig 6. The influence of diet supplements involving SF68 treatments upon levels of plasma $\gamma$-globulin and albumin. The findings were derived from analysis of the densitometrical intensity of the corresponding band in the SDS-PAGE. a,b,c Those values which are indicated using a superscript were significantly different at the different time intervals within the same treatment at the significance level of $P<0.05$. "Significant differences were observed $(P<0.05)$ between the SF68-supplemented group and the control group for similar time intervals.

\section{DISCUSSION}

Based on our past studies that showed improved innate immunity by the commercial E. faecium (SF68) in bovine mammary gland during acute phase response along involution (Peng et al., 2013; Tiantong et al., 2015a; Tiantong et al., 2015b), this work offers further evaluation of the influence of SF68 upon pre-weaning goat kids. Moreover, a feasible usage and effectiveness in the prophylactic control of diarrhea were also reported in buffalo calves (Masucci et al., 2010). Despite no effect on body weight gain as similar to the results from Whitley et al. (2009), we showed an improved innate immune response in pre-weaning goat kids by SF68 supplementation in the colostrum or milk replacer.

An increase of plasma protein contents and $\gamma$ globulin in colostrum by SF68 supplementation may indicate increased passive transfer of the colostral proteins into the circulation, or due to the immune system of newborn per se, which in turn can enhance humoral 
defense in newborn animals. It has been reported that supplementation of SF68 could be increased the plasma IgG concentration along with the pro-inflammatory cytokines which include interleukin-4 (IL-4), IL-6, and interferon- $\gamma$ (IFN- $\gamma$ ) in the mice (Sun et al., 2010). In addition, other research has indicated that the use of probiotics can support the immune system in the region of the intestinal mucosa which can ultimately enhance the production of IgA (Tejada-Simon et al., 1999; Timmerman et al., 2005; Kaburagi et al., 2007).

In SDS-PAGE, IgG1 and IgG2 behave as monomers $(\sim 150 \mathrm{kDa}), \operatorname{IgA}$ as a monomer or a $\operatorname{dimer}(\sim$ $385 \mathrm{kDa})$, while $\operatorname{IgM}$ as a hexamer $(\sim 900 \mathrm{kDa})$ (Elfstrand et al., 2002). Our definition of $\gamma$-globulin should have included all dominated Ig classes in the plasma except IgM. We found acutely increased plasma IgG in goat kids fed E. faecium (SF68). According to study by Sun et al. (2010), the concentration of IgA and IgG rose significantly in the plasma of mice which had been fed probiotics when compared to the control group. This increase is the result of the stimulatory influence of foods, including probiotics, when absorbed via the intestinal epithelial cells into the blood (Cruywagen et al., 1996; Benyacoub et al., 2005). Serum albumin is one of the most abundant proteins in blood plasma in mammal species. Its main function is the regulation of the colloidal osmotic pressure of blood, which it appears to reflect its importance in animal physiology (Lee and $\mathrm{Wu}, 2015$ ). During the course of this study, the greatest albumin level was recorded after $12 \mathrm{~h}$ in goat kids receiving the SF68supplement.

The total leukocyte is a reliable tool for assessing individual animals in measuring the peripheral immune response (Kaplan et al., 2004). In this study, a dramatically increased total leukocyte count by SF68 was observed. Similar results by was also reported in immunosuppressed Wistar rats (Kyakulaga et al., 2013) and by Coriolus versicolor in goats (Kingsley et al., 2016) were also reported.

ROS (reactive oxygen species) are well-known to be an effective part of the immune system in supporting the destruction of invading pathogens. The capacity of ROS production represents the most powerful effect of innate immune systems for further cascades of innate and adaptive immune responses (Tiantong et al., 2015 a). In previous studies, we showed increased ROS production capacity in mammary and peripheral leukocytes of dairy cow receiving SF68 from udder infusion (Peng et al., 2013; Tiantong et al., 2015 a). The response may indicate a mild and physiological immune response as compared to the LPS challenge.

In conclusion, supplementation of E. faecium (SF68) has great potential to improve newborn's health before entering the weaning period. Our findings suggested E. faecium (SF68) had a positive effect on the total plasma protein concentration, $\gamma$-globulin, albumin, total leukocyte counts and the reactive oxygen species (ROS) production, which benefits the newborn's health and may lead to improved production in the following stage such as growth performance.

Acknowledgments: This study received financial support from Silpakorn University, Thailand. The National Chung Hsing University, Taiwan, provided the laboratory equipment used in the study.

\section{REFERENCES}

Abe, F., N. Ishibashi, and S. Shimamura (1995). Effect of administration of Bifidobacteria and lactic acid to newborn calves and piglets. J. Dairy Sci. 78(12): 2838-2846.

Benyacoub, J., P.F. Pérez, F. Rochat, K.Y. Saudan, G. Reuteler, N. Antille, M. Humen, G.L. De Antoni, C. Cavadini, S. Blum, and E.J. Schiffrin (2005). Enterococcus faecium SF68 enhances the immune response to Giardia intestinalis in mice. J. Nutr., 135(5): 1171- 1176.

Braat, H., J. van den Brande, E. van Tol, D. Hommes, M. Peppelenbosch, and S. van Deventer (2004). Lactobacillus rhamnosus induces peripheral hyporesponsiveness in stimulated CD4+ T cells via modulation of dendritic cell function. Am. J. Clin. Nutr. 80(6): 1618- 1625.

Broom, L.J., H.M. Miller, K.G. Kerr, and J.S. Knapp (2006). Effects of zinc oxide and Enterococcus faecium SF68 dietary supplementation on the performance, intestinal microbiota and immune status of weaned piglets. Res. Vet. Sci. 80(1): 45-54.

Bybee, S.N., A.V. Scorza, and M.R. Lappin (2011). Effect of the probiotic Enterococcus faecium SF68 on presence of diarrhea in cats and dogs housed in an animal shelter. J. Vet. Intern. Med. 25(4): 856-860.

Casewell, M., C. Friis, E. Marco, P. McMullin, and I. Phillips (2003). The European ban on growthpromoting antibiotics and emerging consequences for human and animal health. J. Antimicrob. Chemother. 52(2): 159-161.

Cruywagen, C.W., I. Jordaan, and L. Venter (1996). Effect of Lactobacillus acidophilus supplementation of milk replacer on preweaning performance of calves. J. Dairy Sci. 79(3): 483486.

DeNise, S.K., J.D. Robison, G.H. Stott, and D.V. Armstrong (1989). Effects of passive immunity on subsequent production in dairy heifers. J. Dairy Sci. 72(2): 552-554.

Elfstrand, L., L.M. Helena, M. Paulsson, L. Nyberg, and B. Akesson (2002). Immunoglobulins, growth factors and growth hormone in bovine colostrum 
and the effects of processing. Intern. Dairy J., 12(11): 879-887.

Gay, C.C (1983). Failure of passive transfer of colostral immunoglobulins and neonatal disease in calves: a review. Proc.4th Int. Symp. Neonatal Diarrhea Vet. Infect. Dis. Organ. 346-364.

Gill, H. S., K. J. Rutherfurd, and M.L. Cross (2001). Dietary probiotic supplementation enhances natural killer cell activity in the elderly: an investigation of age-related immunological changes. J. Clin. Immunol. 21(4): 264-271.

Kaburagi, T., T. Yamano, Y. Fukushima, H. Yoshino, N. Mito, K. Sato (2007). Effect of Lactobacillus johnsonii La1 on immune function and serum albumin in aged and malnourished aged mice. Nutrition. 23(4): 342-350.

Kaplan, R.M., J.M. Burke, T.H. Terrill, J.E. Miller, W.R. Getz, S. Mobini, E. Valencia, M.J. Williams, L.H. Williamson, M. Larsen, and A.F. Vatta (2004). Validation of the FAMACHA (C) eye color chart for detecting clinical anemia in sheep and goats on farms in the southern United States. Vet. Parasitol. 123: 105-120.

Kingsley, E., E. Asiamah, S. Adjei-Fremah, and M. Worku (2016). Effect of mushroom (Coriolus versicolor) based probiotic on goat health. Am.J. Anim. Vet. Sci. 11(3): 108-118.

Kyakulaga, A.H., P.E. Ogwang, C. Obua, G. Nakabonge, and E.N. Mwavu (2013). Immunomodulatory effects of aqueous extracts of Auricularia sp and Pleurotus $s p$ mushrooms in cyclophosphamide immunosuppressed wistar rats. Brit. J. Pharmaceutical Res. 3(4): 662-670.

Laemmli, U. K (1970). Cleavage of structural proteins during the assembly of the head of bacteriophage T4. Nature. 227(5259): 680-685.

Lee, P., and X. Wu (2015). Review: Modification of human serum albumin and their binding effect. Curr. Pharm. Des. 21(14): 1862-1865.

Maldonado, G.C., A. de Moreno de LeBlanc, G. Vinderola, M.E. Bibas Bonet, and G. Perdigón (2007). Proposed model: mechanisms of immunomodulation induced by probiotic bacteria. Clin. Vaccine Immunol. 14(5): 485492.

Masucci, F., R. Giuseppe De, G. Fernando, N. Fabio, E. Giulia, and F. Antonio Di (2010). Performance and immune response of buffalo calves supplemented with probiotic. Livest. Sci. 137: 24-30.

Peng, H.S., A. Tiantong, S.E. Chen, P. Piya, W.B. Liu, H.C. Peh, J.W. Lee, M.T. Chen, H. Nagahata, and C.J. Chang (2013). Ultrasonicated Enterococcus faecium SF68 enhances neutrophil free radical production and udder innate immunity of drying-off dairy cows. J. Dairy Res. 80(3): 349-359.

Pohjavuori, E., M. Viljanen, R. Korpela, M. Kuitunen, M. Tiittane, O. Vaarala, and E. Savilahti (2004). Lactobacillus GG effect in increasing IFNgamma production in infants with cow's milk allergy. J. Allergy Clin. Immunol. 114(1): 131136.

Poulsen, K.P., A.L. Foley, M.T. Collins, and S.M. McGuirk (2010). Comparison of passive transfer of immunity in neonatal dairy calves fed colostrum or bovine serum-based colostrum replacement and colostrum supplement products. J. Am. Vet. Med. Assoc. 237(8): 949 -954 .

SAS Institute SAS/STAT user's guide (2008). Release 9.2. SAS Institute Inc., Cary, $\mathrm{N}$

Scharek, L., J. Guth, M. Filter, M.F.G. Schmidt (2007). Impact of the probiotic bacteria Enterococcus faecium NCIMB 10415 (SF68) and Bacillus cereus var. toyoi NCIMB 40112 on the development of serum $\operatorname{IgG}$ and faecal $\operatorname{IgA}$ of sows and their piglets. Arch. Anim. Nutr. 61(4): 223-234.

Scharek, L., J. Guth, K. Reiter, K.D. Weyrauch, D. Taras, P. Schwerk, P. Schierack, M.F. Schmidt, L.H. Wieler, and K. Tedin (2005). Influence of a probiotic Enterococcus faecium strain on development of the immune system of sows and piglets. Vet. Immunol. Immunopathol. 105: 151-161.

Schultz, M., H.J. Linde, N. Lehn, K. Zimmermann, J. Grossmann, W. Falk, and J. Schölmerich (2003). Immunomodulatory consequences of oral administration of Lactobacillus rhamnosus strain GG in healthy volunteers. J. Dairy Res. 70(2): 165-173.

Simpson, K.W., M. Rishniw, M. Bellosa, J. Liotta, A. Lucio, M. Baumgart, G. CzarneckiMaulden, J. Benyacoub, and D. Bowman (2009). Influence of Enterococcus faecium SF68 probiotics on Giardiasis in Dogs. J. Vet. Intern. Med. 23(3): 476-481.

Sun, P., J. Wang, and Y. Jiang (2010). Effects of Enterococcus faecium (SF68) on immune function in mice. Food Chem. 123(1): 63-68.

Tejada-Simon, M.V., J.H. Lee, Z. Ustumol, and J.J. Pestka (1999). Ingestion of yogurt containing Lactobacillus acidophilus and bifidobacterium to potentiate immunoglobulin A responses to cholera toxin in mice. J. Dairy Sci. 82(4): 649660 .

Timmerman, H.M.., L. Mulder, H. Everts, D.C. van Espen, E. van der Wal, G. Klaassen, S.M.G. Rouwers, R. Hartemink, F.M. Rombouts, and A.C. Beynen (2005). Health and growth of veal 
calves fed milk replacers with or without probiotics. J. Dairy Sci. 88(6): 2154-2165.

Tiantong, A., P. Piya, S.E. Chen, W.B. Liu, F.Y. Chang, P.C. Lin, H. Nagahata, and C.J Chang (2015a). Systemic and local bactericidal potentiality in late lactation Holstein-Friesian cows following a combined antibiotics and Enterococcus faecium SF68 dry-cow treatment. Jpn. J. Vet. Res. 63(3): 139-150.

Tiantong, A., H.Y. Peng, S.E. Chen, P. Piamya, W.B. Liu, M.T. Chen, C. Yu, H. Nagahata and C.J. Chang (2015b). Intramammary infusion of an enterococcus faecium SF68 preparation promoted the involution of drying off Holstein cows partly related to neutrophil-associated matrix metalloproteinase 9. Anim. Sci. J. 86(1): 111-119.

Veir, J.K., R. Knorr, C. Cavadini, S. J. Sherrill, J. Benyacoub, E. Satyaraj. and M. R. Lappin (2007). Effect of supplementation with Enterococcus faecium (SF68) on immune functions in cats. Vet. Ther. 8(4): 229-238.

Whitley, N.C., D. Cazac, B.J. Rude, D. Jaackson-O' Brien, and S. Parveen (2009). Use of a commercial probiotic supplement in meat goats. J. Anim. Sci. 87(2): 723-728.

Wongsuvan, G., V. Wuthiekanun, S. Hinjoy, N. PJ Day, and D. Limmathurotsakul (2018). Antibiotic use in poultry: a survey of eight farms in Thailand. Bull. World Health Organ. 96: 94-100. 